\title{
Editorial: Implementing Environmental Flows: Lessons for Policy and Practice
}

\author{
David Tickner ${ }^{1,2 *}$, Nitin Kaushal ${ }^{3}$, Robert Speed $^{4,5}$ and Rebecca Tharme ${ }^{6,7,8}$ \\ ${ }^{1}$ WWF-UK, Woking, United Kingdom, ${ }^{2}$ Water Security Research Centre, University of East Anglia, Norwich, United Kingdom, \\ ${ }^{3}$ WWF-India, New Delhi, India, ${ }^{4}$ Badu Advisory, Brisbane, QLD, Australia, ${ }^{5}$ Australian National University, Canberra, ACT, \\ Australia, ${ }^{6}$ Riverfutures, Cressbrook, United Kingdom, ${ }^{7}$ Australian Rivers Institute, Griffith University, Nathan, QLD, Australia, \\ ${ }^{8}$ LE STUDIUM Loire Valley Institute for Advanced Studies, Orléans \& Tours, CITERES, CNRS, University of Tours, Tours, \\ France
}

Keywords: freshwater ecosystems, water resource management, irrigation, dams, water governance, sciencepolicy interface

\section{Editorial on the Research Topic}

\section{Implementing Environmental Flows: Lessons for Policy and Practice}

OPEN ACCESS

Edited by:

Anik Bhaduri,

Griffith University, Australia

Reviewed by:

Ben Stewart-Koster,

Griffith University, Australia

*Correspondence:

David Tickner

dtickner@wwf.org.uk

Specialty section:

This article was submitted to

Freshwater Science,

a section of the journal

Frontiers in Environmental Science

Received: 09 April 2020

Accepted: 22 June 2020

Published: 04 August 2020

Citation:

Tickner D, Kaushal N, Speed $R$ and

Tharme $R$ (2020) Editorial:

Implementing Environmental Flows:

Lessons for Policy and Practice.

Front. Environ. Sci. 8:106.

doi: 10.3389/fenvs.2020.00106
Water resources and freshwater ecosystems are under pressure from a growing human population, thirstier lifestyles, and climate change (UNESCO and UN water, 2020). Consequently, water-related risks to society are increasing (World Economic Forum, 2020) and freshwater biodiversity is rapidly declining (Grooten, 2018). The UN Sustainable Development Goals (SDGs) include targets for improved water management, including SDG 6.4, which stipulates sustainable water withdrawals, and SDG 6.6, aimed at halting the degradation of water-related ecosystems. The hydrological regimes of rivers and other wetlands can be regarded as a litmus test of whether these targets are met (Tickner and Acreman, 2013). Environmental flow assessment (EFA) is the science-based process of determining appropriate flow regimes for individual water bodies given environmental, socioeconomic and cultural objectives. Researchers have developed sophisticated EFA tools (Acreman et al., 2014; Poff et al., 2017) but implementation of environmental flows has been problematic, and research into the challenges of implementation is scarce.

Case studies of environmental flow implementation, successful or otherwise, provide valuable insights into barriers and enabling factors, and illustrate the evolution and propagation of environmental flow practice globally. The Murray-Darling River, Australia, is among the most studied and contested of such cases. Stimulated by severe drought, the Federal Government instigated a basin-wide water allocation planning process in the mid-2000s. Gawne et al. describe the use of conceptual models in the development of the basin plan. They argue that such models inform the setting of ecological objectives, support decision-making where data are scarce, and help integration of basin- and local-scale analyses. As with the Murray-Darling, the ecological condition of the River Ganga, India, has been adversely affected by a high demand for irrigation water. The Ganga is spiritually revered by hundreds of millions of people and the Government of India has placed a high priority on its restoration. Kaushal et al. document approaches to understand and resolve potential trade-offs between environmental flow objectives for the Ganga in Uttar Pradesh and agricultural water demand. They conclude that, contrary to common perceptions, the increase in water needed to restore flows is likely to be small compared to overall water demand. Moreover, agricultural water efficiency measures can ameliorate potential adverse impacts on farmers from changes in water allocation. On a similar theme, Linstead et al. draws on an increasing body of literature that warns of perverse outcomes from increasing irrigation efficiency. He suggests 
that an effective water allocation regime that explicitly accounts for environmental flows is a pre-requisite if agricultural water savings are to lead to ecological benefits. Even where such an allocation regime exists, he argues that analysis at multiple spatiotemporal scales is necessary to understand the implications for environmental flows of changes to irrigation. Richards and Syallow also analyse the challenges of reconciling farmers' water needs with environmental flows, but at a more local scale. Focusing on village-level Water Resource User Associations (WRUAs) along the Mara River, Kenya, they identify progress in local discourse about sustainable water use, and potential pitfalls of which water managers, NGOs and others pursuing environmental flow implementation should be aware. These include elite capture, donor dependency and a lack of meaningful participation opportunities.

Dams built for hydropower and other uses can substantially impact hydrological regimes, as well as fragmenting aquatic habitats (Grill et al., 2019). Drawing on North American experiences in dam re-operation, Opperman, Kendy and Barrios set out two pathways for embedding environmental flow implementation in the siting, design and operation of water infrastructure. The first emphasizes the potential for basin or jurisdiction-scale policy and management to catalyze implementation efforts widely. The second focuses on measures for specific dams or river reaches of high conservation value. Critically, these two pathways should, wherever possible, be nested such that management efforts are integrated across scales. King and Brown also endorse system-scale assessments of likely infrastructure impacts. They issue a welcome call for integration of EFA as an early stage in Cumulative Impact Assessments (CIAs) of planned dams across river basins, with context-specific selection of EFA methods. Cheng et al. describe the problems for downstream fisheries caused by the Three Gorges Dam on the Yangtze River, China. They document experiments with flow releases from the dam over a 5-year period that have shown the potential for partial mitigation of the decline in fish recruitment without compromising hydropower generation and flood protection. As in the other case studies, future success will depend on continued monitoring, stakeholder engagement, and adaptive management.

Four papers in this Research Topic set out agendas for future research, policy, and practice on environmental flow implementation. Horne et al. report on a horizonscanning exercise that explored research priorities for improving outcomes from environmental water management. Six themes emerged, including adaptive management, knowledge transfer, and community engagement. Opperman, Kendy, Tharme et al. noted the recent diversification of EFA methods and the need for guidance to practitioners and policy makers as to which method might best suit their context. They suggest a threelevel framework-with levels of complexity increasing with each level-for ensuring that approaches to assessment and implementation of environmental flows are linked, and that implementation happens as early as possible. Harwood et al. also consider the policy dimensions of environmental flow implementation. Drawing on eight case studies of "successful" implementation from around the world, they distill critical enabling factors that can provide a foundation for effective policies. These include the existence of appropriate legislation and regulation, collaboration, and leadership, resources and capacity, and monitoring and adaptive management. Capon et al. explore the necessity for environmental flow implementation to be resilient to climate change. They point out that many EFA methods rely on outdated assumptions of hydrological stationarity that might lead to flawed implementation plans. Urging a re-evaluation of conventional approaches, they put forward proposals for adapting objective-setting, planning, and management of water resources to take account of climatic uncertainties.

Cutting across the themes and cases described above, O'Keeffe presents a personal perspective on the need for improved training on assessment, policy, and practice for environmental flow implementation. He describes the evolution of a training approach that was pioneered in partnerships with academic, government, and NGO practitioners. He makes a compelling case for securing three ingredients for successful training and implementation that is adaptable to multiple settings: local champions, with a long-term commitment; understanding and support from stakeholders; and a process that is, initially at least, as simple as possible and that demonstrates quick implementation successes.

The Brisbane Declaration (2007) was a seminal document in global research and policy on environmental flows. Endorsed by hundreds of experts and setting out a common vision for implementation, it guided subsequent efforts worldwide. Arthington et al. describe the extensive consultation process to update the Declaration, a decade on. They present the resulting 2018 Brisbane Declaration with its revised environmental flow definition and urgent call for action to implement environmental flows as a foundation for achieving water-related SDGs. The accompanying Global Action Agenda outlines the pathway for a new era of collaborative endeavor, to more effectively bridge the science-policy interface and accelerate implementation.

The papers in this Research Topic draw on experiences from multiple regions and a wide range of perspectives. As such, they provide a unique blend of insights into the connections (or lack thereof) between research, policy and practice. It is clear that progress is being made; environmental flows are being implemented in rivers and wetlands internationally. Equally, a combination of technical, environmental, socio-economic, cultural, and political complexities will mean that ensuring sustainable water use, and maintaining or restoring freshwater ecosystems, will continue to be challenging. Many of the papers provide explicit recommendations that will help policy makers and practitioners to navigate these challenges. For instance, a clear focus from the outset on supporting the establishment of durable enabling conditions for more sustainable water allocation and infrastructure development processes is crucial. Ensuring robust conceptualization and sufficient knowledge of the natural and social processes that influence water management at multiple scales is also important. Approaches to implementation that explicitly consider future uncertainties are likely to be more resilient than those which are based entirely on past conditions. Choosing the right environmental flow assessment method for 
the context is always helpful, as is demonstration of early success. There is ample scope for further analysis that delves deeper into lessons from a wider range of cases, especially with respect to social sciences aspects (Anderson et al., 2019) and impacts of implementation on freshwater biodiversity. It will be essential to revisit the insights in this Research Topic in due course to further inform future policy and practice. In the meantime, implementation efforts that are inclusive, pragmatic, adaptive, and multi-disciplinary can bear fruit even where knowledge gaps remain.

\section{DEDICATION}

On behalf of the global environmental flow community, we dedicate this Research Topic on environmental flow implementation to our beloved friend and colleague, the late

\section{REFERENCES}

Acreman, M., Arthington, A. H., Colloff, M. J., Couch, C., Crossman, N. D., Dyer, F., et al. (2014). Environmental flows for natural, hybrid, and novel riverine ecosystems in a changing world. Front. Ecol. Environ. 12,-466-473. doi: $10.1890 / 130134$

Anderson, E. P., Jackson, S., Tharme, R. E., Douglas, M., Flotemersch, J. E., Zwarteveen, M., et al. (2019). Understanding rivers and their social relations: a critical step to advance environmental water management. Wiley Interdiscipl. Rev. Water 6:e1381. doi: 10.1002/wat2.1381

Brisbane Declaration (2007). "The Brisbane Declaration: environmental flows are essential for freshwater ecosystem health and human well-being," in 10th International River Symposium and International Environmental Flows Conference (Brisbane, QLD).

Grill, G., Lehner, B., Thieme, M., Geenen, B., Tickner, D., Antonelli, F., et al. (2019). Mapping the world's free-flowing rivers. Nature 569, 215-221. doi: 10.1038/s41586-019-1111-9

Grooten, M. and Almond, R. (2018). Living Planet Report-2018: Aiming Higher. Gland: WWF.

Poff, N. L., Tharme, R. E. and Arthington, A. H. (2017). "Evolution of environmental flows assessment science, principles, and methodologies," in
Jay O'Keeffe, Emeritus Professor at Rhodes University, South Africa. Jay was a global pioneer and thought leader in the field of environmental flows. Throughout his career, he contributed his passion, deep insights, on-the-ground experience, and boundless energy to help create the interdisciplinary foundation on which so many other practitioners have been able to build. His true commitment to the mentoring and training of young professionals nurtured a growing capacity for environmental flow implementation in the Global South. We are committed to ensuring his legacy is an enduring one.

\section{AUTHOR CONTRIBUTIONS}

DT drafted the manuscript. NK, RS, and RT contributed to revisions of the manuscript. All authors contributed to the article and approved the submitted version.
Water for the Environment, eds A. C. Horne, J. A. Webb, M. J. Stewardson, B. Richter, and M. Acreman (London: Academic Press), 203-236.

Tickner, D., and Acreman, M. (2013). "Water security for ecosystems, ecosystems for water security," in Water Security: Principles, Perspectives and Practices, eds B. Lankford, K. Bakker, M. Zeitoun and D. Conway (London: Routledge).

UNESCO and UN water (2020). United Nations World Water Development Report 2020: Water and Climate Change. Paris: UNESCO.

World Economic Forum (2020). Global Risks Report. Geneva: World Economic Forum.

Conflict of Interest: DT was employed by WWF-UK. NK was employed by WWF India. RS was employed by the company Badu Advisory Pty Ltd. RT was employed by Riverfutures Ltd.

Copyright ( 2020 Tickner, Kaushal, Speed and Tharme. This is an open-access article distributed under the terms of the Creative Commons Attribution License (CC BY). The use, distribution or reproduction in other forums is permitted, provided the original author(s) and the copyright owner(s) are credited and that the original publication in this journal is cited, in accordance with accepted academic practice. No use, distribution or reproduction is permitted which does not comply with these terms. 